\title{
EFFECTS OF PRIOR EXERCISE ON THE PERFORMANCE OF INTENSE ISOMETRIC EXERCISE
}

\author{
R. J. MAUGHAN \\ Department of Environmental and Occupational Medicine, University Medical School, Aberdeen
}

\section{ABSTRACT}

The influence of a regimen designed to lower the muscle glycogen content on the capacity to perform a single brief isometric contraction has been studied. Eight male subjects performed a single exhausting isometric contraction of the knee extensor muscles at a tension corresponding to $60 \%$ of maximum voluntary contraction (MVC). This was followed by prolonged cycling exercise at a work rate equivalent to approximately $75 \%$ of maximum oxygen uptake in order to reduce the muscle glycogen content. A diet low in carbohydrate was consumed for the remainder of this day in order to retard the resynthesis of muscle glycogen. The isometric contraction at $60 \%$ of MVC was repeated on the following day. Endurance time on the first day was $53.8 \pm 8.4 \mathrm{~s}$ (mean $\pm \mathrm{SD}$ ); this was reduced $(45.8 \pm 12.1 \mathrm{~s} ; \mathrm{p}<0.02)$ on the second day. From previously published data on rates of muscle glycogen utilisation during isometric exercise, it seems probable that insufficient glycogen is available in the muscle under the low carbohydrate condition to enable maximum performance to be achieved.

Key words: Isometric exercise, Fatigue, Lactic acid, Glycogen

\section{INTRODUCTION}

During intense dynamic muscular exercise, the energy requirements of the contracting muscles are met by depletion of creatine phosphate (CP), by anaerobic glycolysis and by oxidative metabolism. Fatigue results from the inability to maintain the energy supply at the required rate. The reasons for this reduction in the rate of energy provision are not clear. In prolonged cycle exercise, Bergström et al (1967) established that the point of exhaustion was related to depletion of the intramuscular glycogen stores. Saltin and Karlsson (1971), however, showed that in high intensity work on the cycle ergometer, at loads in excess of $90 \%$ of maximum oxygen uptake $\left(\mathrm{VO}_{2}\right.$ max), the subjective sensation of fatigue caused work to be terminated in spite of the presence of a relatively high muscle glycogen content at the point of fatigue. This can be interpreted as an indication that the performance of high intensity work is not limited by the availability of substrate in the form of muscle glycogen. In contrast to these findings, Åstrand et al (1963) and Klausen et al (1975) have demonstrated that the capacity to perform brief intense cycle exercise is diminished if this is preceded by a prolonged exhausting work bout. More recently, we have shown that the performance of supramaximal cycle exercise can be influenced by a dietary regimen designed to produce changes in the muscle glycogen content (Maughan and Poole, 1981). When the muscle glycogen content is reduced by prolonged exercise and the administration of a low-carbohydrate $(\mathrm{CHO})$ diet, the endurance time is decreased. Conversely performance is enhanced by consumption of a high-CHO diet prior to the exercise test. This study suggests that the ability to supply energy by anaerobic glycolysis may be dependent upon muscle glycogen content.

During sustained isometric muscle contractions, anaerobic glycogenolysis represents the major energy source. The rise in intramuscular pressure occasioned by the contraction results in partial or total occlusion of the blood vessels, limiting the delivery of oxygen and circulating substrates and the removal of the end products

Address for correspondence:

Dr. R. J. Maughan

Department of Environemental and Occupational Medicine

University of Aberdeen

Ashgrove Road West

Aberdeen AB9 2ZD of metabolism (Barcroft and Millen, 1939). It is not clear at what point the blood flow is completely occluded, but at tensions in excess of $15 \%$ of maximum voluntary contraction (MVC) the blood flow is inadequate for the metabolic requirements of the muscle (Donald et al, 1967). In view of the importance of the availability of muscle glycogen as an energy-providing substrate in this situation, it seems surprising that little consideration has been given to the possible role of changes in the muscle glycogen content in determining the capacity to perform work of this type. The present study has compared the ability to sustain a brief intense contraction under differing conditions of glycogen availability.

\section{METHODS}

Eight healthy young adult males acted as subjects. In terms of their capacity to perform both dynamic and isometric exercise they represent a rather heterogeneous group; some took part in regular physical activity, although none was particularly well trained at the time of the study, whereas others had no regular exercise. The physical characteristics of the subjects are presented in Table I. Informed consent was obtained in writing from each subject prior to the study which was approved by the local Ethics Committee.

\section{TABLE I}

Physical characteristics and Maximum Voluntary Contraction (MVC) of subjects.

\begin{tabular}{cccccc}
\hline $\begin{array}{c}\text { Subject } \\
\text { No. }\end{array}$ & $\begin{array}{c}\text { Age } \\
\text { (year) }\end{array}$ & $\begin{array}{c}\text { Height } \\
(\mathrm{cm})\end{array}$ & $\begin{array}{c}\text { Weight } \\
\text { (kg) }\end{array}$ & $\begin{array}{c}\text { MVC } \\
\text { (N) }\end{array}$ & $\begin{array}{c}\text { MVC } \\
\text { (N.kg-1 b.w.) }\end{array}$ \\
\hline 1 & 32 & 174 & 63.5 & 492 & 7.75 \\
2 & 30 & 174 & 71.0 & 649 & 9.32 \\
3 & 24 & 178 & 66.6 & 565 & 8.43 \\
4 & 21 & 178 & 64.1 & 666 & 10.40 \\
5 & 33 & 160 & 61.3 & 589 & 9.61 \\
6 & 24 & 184 & 82.8 & 729 & 8.83 \\
7 & 25 & 169 & 75.8 & 652 & 8.63 \\
8 & 33 & 170 & 76.2 & 465 & 6.08 \\
\hline
\end{tabular}

Isometric exercise was performed with the subject seated in a chair similar to that described by Tornvall (1963). Tension produced by exerting force with the knee extensor muscles was recorded via a strain gauge and displayed on a 
rapid response pen recorder. In all contractions the knee joint was held at a right angle. For each subject, MVC was recorded as the best performance produced in three or four attempts. Previous experience with this apparatus had indicated that no subject was able to improve his performance if given further trials. Each subject was also given at least one practice attempt at sustaining to fatigue a contraction representing $60 \%$ of his MVC in order to familiarise him with the sensation of localised fatigue experienced in exercise of this type. This was performed at least one week prior to each subject's first experimental test. During the sustained contraction, subjects were required to superimpose the recorder pen on a line previously drawn on the chart to correspond to the required tension. Verbal encouragement was provided in an attempt to elicit maximum performance.

One week after these preliminary tests, subjects reported to the laboratory at 9 a.m. after an overnight fast. Each subject then sustained a contraction at $60 \%$ of his MVC to the point of fatigue. Blood samples were obtained by fingerprick from a pre-warmed hand prior to the exercise and at intervals during the recovery period. Lactate concentration was measured as previously described (Maughan, 1982). After a short rest, subjects pedalled to exhaustion on a cycle ergometer at a work load corresponding to approximately $75 \%$ of $\mathrm{VO}_{2}$ max. All subjects completed at least one hour's exercise. This type of prolonged cycling exercise has been shown by Hermansen et al (1967) to result in almost total depletion of glycogen in $\mathrm{m}$. quadriceps femoris, the same muscle group involved in the performance of the isometric work. For the remainder of this day, the carbohydrate intake of the subjects was restricted as previously described (Maughan and Poole, 1981). After an overnight fast, the isometric exercise was repeated on the following morning under the same conditions as on the first day.

The statistical significance of differences between results under the two different conditions was assessed by the use of Student's t-test for paired data.

\section{RESULTS}

On the first test, the time for which the contraction could be maintained was $53.8 \pm 8.4 \mathrm{~s}$ (Mean $\pm \mathrm{SD}$ ); on the second test this was reduced to $45.8 \pm 12.1 \mathrm{~s}(p<0.02)$. These results are presented in Table II. This decrease in performance was accompanied by a loss of body weight $(p<0.001)$ which decreased from $70.2 \pm 7.6 \mathrm{~kg}$ to $69.1 \pm 7.6 \mathrm{~kg}$

TABLE ||

Effects of the experimental procedure on isometric endurance time and body weight.

\begin{tabular}{cccrrrrr}
\hline \multirow{2}{*}{$\begin{array}{c}\text { Subject } \\
\text { No. }\end{array}$} & \multicolumn{3}{c}{ Endurance Time(s) } & \multicolumn{3}{c}{ Body Weight (kg) } \\
& Day 1 & Day 2 & $\Delta$ & Day 1 & Day 2 & \multicolumn{1}{c}{$\Delta$} \\
\hline 1 & 46 & 41 & -5 & 63.5 & 62.1 & -1.4 \\
2 & 44 & 37 & -7 & 71.0 & 70.0 & -1.0 \\
3 & 59 & 46 & -13 & 66.6 & 65.6 & -1.0 \\
4 & 47 & 47 & 0 & 64.1 & 62.3 & -1.8 \\
5 & 66 & 61 & -5 & 61.3 & 60.7 & -0.6 \\
6 & 52 & 36 & -16 & 82.8 & 81.5 & -1.3 \\
7 & 52 & 32 & -20 & 75.8 & 74.9 & -0.9 \\
8 & 64 & 66 & +2 & 76.2 & 75.5 & -0.7 \\
Mean & 54 & 46 & -8 & 70.2 & 69.1 & -1.1 \\
SD & 8 & 12 & 8 & 7.6 & 7.6 & 0.3 \\
\hline
\end{tabular}

on the second day. No attempt was made to take into account any effect of this decrease in body weight on MVC. Mean endurance time for the prolonged cycling exercise was $74 \pm 6 \mathrm{~min}$, at a workload corresponding to $73 \pm 1 \%$ of $\mathrm{VO}_{2}$ max. Subjects were encouraged to ensure adequate fluid intake following the prolonged cycling exercise to avoid the possible influence of cellular dehydration on performance. The decrease in body weight probably represents a loss of muscle glycogen together with its associated water.

There was no difference in resting blood lactate concentration between the two tests (Fig. 1). A rapid rise in the blood lactate concentration occurred in the postexercise period. Throughout the recovery period, blood lactate concentration was higher $(p<0.02)$ on the first day than on the second day.

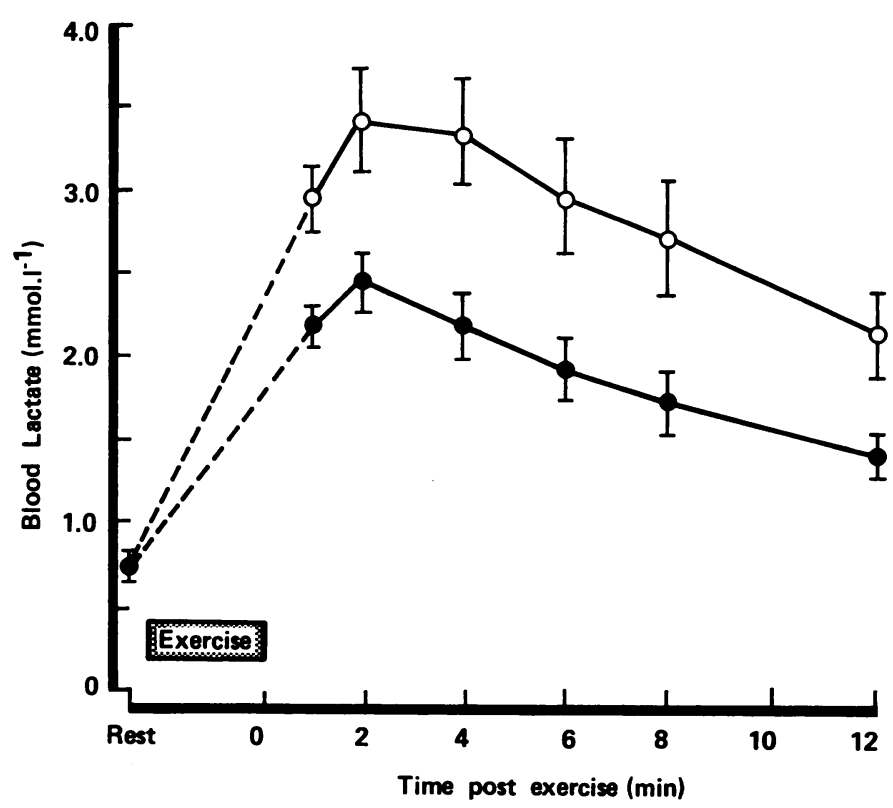

Fig. 1: Blood lactate concentration before and after a single exhausting isometric contraction at $60 \%$ of MVC under conditions of normal $(0)$ and low (•) glycogen availability. Points represent mean values $\pm S E M$. $(n=8)$.

\section{DISCUSSION}

The present study was designed to test the hypothesis that the capacity to perform isometric exercise can be reduced if this is preceded by prolonged dynamic exercise. The results obtained are in agreement with earlier reports that the ability to perform high intensity cycling exercise of short duration is reduced if this is preceded by prolonged work (Åstrand et al, 1963; Asmussen et al, 1974). It is not clear, however, what limits the capacity to perform isometric muscle contractions, or why this should be influenced by the procedures used in the present study.

During intense exercise, the rate of pyruvate formation by glycolysis exceeds the rate at which it can be removed by oxidative metabolism. The excess pyruvate is converted to lactate which accumulates in the muscle cells together with the associated hydrogen ions. This increase in hydrogen ion activity is partially buffered within the cell but, if it exceeds the cellular buffering capacity, it may impair exercise capacity (Tesch, 1980). A fall in $\mathrm{pH}$ may inhibit the activation of myosin ATPase by calcium ions, and may also reduce energy production by glycolysis due to an inhibition of phosphofructokinase. Apart from glycolysis, the other 
major source of energy in intense isometric contractions is from the hydrolysis of intramuscular creatine phosphate, and depletion of creatine phosphate has been considered as à possible limiting factor (Hultman and Bergström, 1973; Katz et al, 1980).

It is also possible that depletion of muscle glycogen stores may reduce the rate of glycolysis below that necessary to maintain the required rate of energy production. A number of reports, however, have shown that availability of glycogen is not normally likely to be a limiting factor in this situation (e.g. Ahlborg et al, 1972; Hultman and Bergström, 1973). Harris et al (1981) studied the metabolic response of subjects to a sustained contraction at $66 \%$ of MVC using an exercise model similar to that employed in the present investigation. They found that a single exhausting contraction lasted $40-45 \mathrm{~s}$, and was accompanied by a glycogen utilisation in the muscle of $80.4 \mathrm{mmol}$ glycosyl units per $\mathrm{kg}$ dry muscle (mmol. $\mathrm{kg}^{-1}$ d.w.). Karlsson and Ollander (1972), using a slightly different exercise model, measured glycogen utilisation in the quadriceps femoris muscle during sustained contractions at 75 and $50 \%$ of MVC. They found an average reduction in muscle glycogen content of 108 and $100 \mathrm{mmol} . \mathrm{kg}^{-1}$ d.w. respectively for these two different exercise intensities. The normal glycogen content of muscle samples obtained from

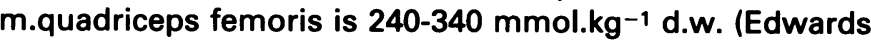
et al, 1975). A single contraction thus results in the breakdown of only $25-40 \%$ of the total muscle glycogen.

During prolonged cycle exercise at a work load corresponding to $75 \%$ of $\mathrm{VO}_{2}$ max, the muscle glycogen content progressively falls; at the point of exhaustion, glycogen is almost completely absent from m.quadriceps femoris (Hermansen et al, 1967). The resynthesis of muscle glycogen in the post-exercise period is dependent upon an adequate dietary $\mathrm{CHO}$ intake (Ahlborg et al, 1967). Pernow and Saltin (1971) reported that prolonged exhausting cycle exercise of $1-1.5 \mathrm{~h}$ duration caused a reduction in the glycogen content of samples obtained from m.vastus lateralis from $280 \mathrm{mmol} . \mathrm{kg}^{-1}$ d.w. to $5-10 \mathrm{mmol} . \mathrm{kg}^{-1}$ d.w. Twenty-four hours later, with only fat and protein being consumed during the intervening period, as in the present study, the muscle glycogen content had increased to reach a mean value of $70 \mathrm{mmol} . \mathrm{kg}^{-1} \mathrm{~d} . \mathrm{w}$. Hultman and Bergström (1967) measured the rate of glycogen resynthesis after exercise in subjects given a low-CHO diet. They found that the mean rate of increase of muscle glycogen under these conditions was approximately $30 \mathrm{mmol} \cdot \mathrm{kg}^{-1} \mathrm{~d}$.w. per day.

Comparison of these results with those of Karlsson and Ollander (1972) and Harris et al (1981) suggests that the provision of energy by anaerobic glycogenolysis under the low-CHO condition on the second day of the present study may not be sufficient to sustain a contraction of comparable duration to that achieved under normal glycogen conditions. It is, of course, possible that there may be a selective depletion of glycogen in a particular population of muscle fibres. Prolonged cycle exercise to exhaustion at 70 $75 \% \mathrm{VO}_{2}$ max will reduce the glycogen content of all fibre types, and glycogen content will fall to almost zero in Type I fibres (Gollnick et al, 1973). Type IIA fibres may be depleted to a similar extent, but it is likely that significant amounts of glycogen will remain in Type IIB fibres at exhaustion (Vøllestad et al, 1984). During isometric contractions of the knee extensor muscles at forces greater than $25 \% \mathrm{MVC}$, preferential depletion of the Type II fibres occurs (Karlsson, 1973), and there may be no change in the glycogen content of Type I fibres (Gollnick et al, 1975). It may be, therefore, that even though the total muscle glycogen content was reduced on the second day of the present study, there was adequate glycogen available in the Type II fibres to sustain a high rate of glycolysis. Lack of glycogen in Type I fibres would, however, reduce their contribution to the performance of the isometric contraction, placing a greater load on the Type II fibres.

An alternative explanation for the reduced exercise capacity observed on the second day is the existence of a metabolic acidosis prior to exercise induced by the low $\mathrm{CHO}$ diet. It is known that pre-existing acidosis induced by ingestion of ammonium chloride will reduce isometric endurance capacity at a force of $50 \%$ MVC (Maughan et al, 1986). Studies in our laboratory have shown that feeding a low $\mathrm{CHO}$, high fat, high protein diet similar to that given to subjects in the present study will result in a slight metabolic acidosis, largely as a consequence of increases in the circulating concentrations of organic acids (free fatty acids and keto-acids) and plasma proteins (unpublished observations). This diet-induced acidosis may contribute to the reduced endurance capacity observed in this study.

In conclusion, therefore, although these results show a reduction in the capacity to perform intense isometric endurance exercise lasting less than 1 minute when it is preceded by prolonged exercise and restriction of $\mathrm{CHO}$ intake, the mechanism by which this response is produced is not clear.

\section{References}

Ahlborg, B., Bergström, J., Brohult, J., Ekelund, L. G., Hultman E. and Maschio, G., 1967 "Human muscle glycogen content and capacity for prolonged exercise after different diets". Forsvarsmedicin 3: 85-89.

Ahlborg, B., Bergström, J., Ekelund, L. G., Guarnieri, G., Harris, R. C., Hultman, E. and Nordesjo, L. O., 1972 "Muscle metabolism during isometric exercise performed at constant force". J.Appl.Physiol. 33: 224-228.

1974 "Lactate production and anaerobic work capacity after prolonged exercise". Acta Physiol.Scand. 90: 731-742.

Åstrand, P. O., Hallback, I., Hedman, R. and Saltin, B., 1963 "Blood lactates after prolonged severe exercise in man". "J.Appl.Physiol. 18: 619-622.

Barcroft, H. and Millen, J. L. E., 1939 "The blood flow through muscle during sustained contraction". J.Physiol. 97: 17-31.

Bertström, J., Hermansen, L., Hultman, E. and Saltin, B., 1967 “Diet, muscle glycogen and physical performance". Acta Physiol.Scand. 71: 140-150.

Donald, K. W., Lind, A. R., McNicol, G. W., Humphreys, P. W., Taylor, S. H. and Staunton, H. P., 1967 "Cardiovascular responses to sustained (static) contractions". Circulation Res.Suppl. 1 to Vols. $X X$ and XXI: 1-15.

Edwards, R. H. T., Jones, D. A., Maunder, C. and Batra, G. J., 1975 “Needle biopsy for muscle chemistry". Lancet I: 736-740.

Gollnick, P. D., Armstrong, R. B., Saubert, C. W., Sembrowich, W. L., Shepherd, R. E. and Saltin, B., 1973 "Glycogen depletion patterns in human skeletal muscle fibres during prolonged work". Pflüg Arch. 344: 1-12.

Gollnick, P. D., Piehl, K., Karlsson, J. and Saltin, B., 1975 “Glycogen depletion patterns in human skeletal muscle fibres after varying types and intensities of exercise". In: Howald, H., Poortmans, J. (eds.) Metabolic adaptations to prolonged exercise. Birkhauser, Basel, p. 145.

Harris, R. C., Hultman, E. and Sahlin, K., 1981 "Glycolytic intermediates in human muscle after isometric contraction". Pflugers Arch. 389: 277-282.

Hermansen, L., Hultman, E. and Saltin, B., 1967 "Muscle glycogen during prolonged severe exercise". Acta Physiol.Scand 71: 129-139.

Hultman, E. and Bergström, J., 1967 "Muscle glycogen synthesis in relation to diet studied in normal subjects". Acta Med.Scand. 182: 109-117.

Hultman, E. and Bergström, J., 1973 "Local energy-supplying substrates as limiting factors in different types of leg muscle work in normal man". In: Keul, J. (ed.) Limiting factors of physical performance. Thieme, Stuttgart, pp. 113-125.

Karlsson, J., 1973 "Isometric leg exercise and glycogen depletion in fast twitch (FT) and slow twitch (ST) fibres in human skeletal muscle". Acta Physiol.Scand.Suppl. 396: 72.

Karlsson, J. and Ollander, B., 1972 "Muscle metabolites with exhaustive static exercise of different duration". Acta Physiol.Scand. 86: 309-314.

Katz, A., Sahlin, K. and Henriksson, K., 1986 "Muscle ATP turnover rate during isometric contraction in humans". J.Appl.Physiol. 60: 1839-1842. 
Klausen, K., Piehl, K. and Saltin, B., 1975 "Muscle glycogen stores and the capacity for anaerobic work". In: Howald, H., Poortmans, J. (eds.) Metabolic adaptations to prolonged exercise. Birkhauser, Basel, pp. 127-129.

- Maughan, R. J., 1982 "A simple, rapid method for the determination of glucose, lactate, pyruvate, alanine, 3-hydroxybutyrate and acetoacetate in a single $20 \mu \mathrm{l}$ blood sample". Clin.Chim.Acta 122: 231-240.

Maughan, R. J. and Poole, D. C., 1981 "The effects of a glycogen-loading regimen on the capacity to perform anaerobic exercise". Eur.J.Appl. Physiol. 46: 211-219.

Maughan, R. J., Leiper, J. B. and Litchfield, P. E., 1986 “The effects of induced acidosis and alkalosis on isometric endurance capacity in man". Exercise Physiology (Dotson, C. O., Humphrey, J. H., eds.) Vol. 2, AMS Press, New York, pp 73-82.
Pernow, B. and Saltin, B., 1971 "Availability of substrates and capacity for prolonged heavy exercise in man". J.Appl.Physiol. 31: 416-422.

Saltin, B. and Karlsson, J., 1971 "Muscle ATP, CP and lactate during exercise after physical conditioning". Adv.Exp.Med.Biol. 11: 395-399.

Tesch, P., 1980 "Muscle fatigue in man". Acta Physiol.Scand.Suppl. 480.

Tornvall, G., 1963 "Assessment of physical capabilities with special reference to the evaluation of maximal voluntary isometric muscle strength and maximal working capacity". Acta Physiol.Scand. 50: Suppl. 201.

Vøllestad, N. K., Vaage, O. and Hermansen, L., 1984 "Muscle glycogen depletion patterns in type I and subgroups of type II fibres during prolonged severe exercise in man". Acta Physiol.Scand. 122: 433-441.

\section{BOOK REVIEW}

Title:

Editor:

Publishers:

\section{SPORTS WOMEN}

M. J. Adrian

Karger, Basel

Price: US \$98.75 (Subject to change)
160 pages. 14 Figs. 14 Tables

This is the 24th volume in a series on Medicine and Sports Science. The orientation is very much towards the situation in the United States from whence come the authors of eight of the eleven chapters with five of these coming from the University of Illinois as does the volume editor.

The first chapter looks at the effect of physical activity on the skeleton and is perhaps the most relevant in the volume. It is unfortunate that with such a lot of data available on the subject at present, there is a lack of up-to-date references, with the author using only one from 1985 and one from 1986, all others being prior to these dates. Chapter Two is about the female breast and, though interesting, is perhaps unnecessary, as it does not actually give rise to many problems in female sports partcipants. The following chapter on acupuncture is a little misplaced in this book, it would seem to be by chance that seventeen of eighteen subjects were female and hence its appearance in this volume. A study was performed with the aim of assessing whether acupuncture reduced fatigue but this did not seem to be the case and the one male subject responded in the same way as the females. The volume editor then contributes a chapter on different physical characteristics in young female basketball and cross-country runners, although it is pointed out that the general design and implications of the study could be expanded to cover other sports. There would appear to be differences between the two groups but whether these are the result of participation within the sport or have been the reasons for direction to the particular sport is uncertain. Interestingly, it was questioned whether less fit girls might gravitate towards cross-country whilst fitter ones participated in basketball which would not be reflected in these sports in Great Britain. A chapter on the effect of visual impairment on physical activity follows, which, although in descriptive terms relates to females, could apply equally well to males and the references used to supply the information do not appear to have been sex specific. Two references are quoted which do not appear in the list following the chapter. The longest chapter then follows and represents a British contribution on psychological research and the sportswoman. This is a very comprehensive chapter going into considerable depth and would be a useful reference source for anyone interested in the subject. One hundred and six references quoted are arranged in a different system (as is the case in the final chapter) to the other chapters in the book. Women in leisure activities in ancient Greece and Rome follows and might more suitably have been placed at the beginning. This makes interesting reading, particularly to learn that Greek women suffered the death penalty if they spectated at the eclusively male Olympic Games (presumably this was because they should have been at home doing housewifely things!). A section on sociological aspects follows. This introduces the concept of 'Title IX' which covers federal legislation which prohibits sex discrimination in athletes in the United States. A small personal study forms the basis of this section and with somewhat inconclusive results. The changing role of sport among intercollegiate female athletes follows, again relating to a personal study the main outcome of which seems to be that interest in sport declines as the individuals move through college. Following this there is a further personal study exploring gender differences in children's motor skills. The study was based on a questionnaire with only a $56 \%$ return rate and there were certain features throwing doubt on this being a representative sample. Two large tables of correlation coefficients add nothing. The final chapter deals with legal aspects mainly covering cases that have occurred in the United States and reporting various court cases.

I was disappointed in this volume with the standard being far below that of three earlier volumes that I have seen in the series. It is over-priced for the British market and has little to recommend it, except, perhaps, as an occasional reference book in a library when three or four of the chapters might prove to be of use. The index is adequate but there are a few typing errors.

Wendy N. Dodds 